\title{
Kuvars Kumunun Kırılma Hızının Tanımlanmasında Öğütücü Ortam Boyutunun Etkisinin Araştırılması
}

\author{
Serhan Haner ${ }^{1 *}$ \\ 1* Afyon Kocatepe Üniversitesi, DUBYO, Endüstriyel Tasarım Bölümü, Afyonkarahisar, Türkiye, (ORCID: 0000-0002-8579-078X), serhan.haner@ gmail.com
}

(İlk Geliş Tarihi 22 Şubat 2021 ve Kabul Tarihi 9 Nisan 2021)

(DOI: $10.31590 /$ ejosat.884565)

ATIF/REFERENCE: Haner, S. (2021). Kuvars Kumunun Kırılma Hızının Tanımlanmasında Öğütücü Ortam Boyutunun Etkisinin Araştırılması. Avrupa Bilim ve Teknoloji Dergisi, (23), 547-551.

$\ddot{O ̈ z}$

Seramik endüstrisinde hammadde hazırlama süreçlerinin ilk aşamasını öğütme üniteleri oluşturmaktadır. Değirmen fazını oluşturan feldispat ve kuvars kumu gibi özsüz hammaddelerin belirli bir tane boyutunun altına indirilmesi uzun süreler almaktadır. Bu durum da zaman ve enerji tüketimi açısından olumsuzluklara neden olmaktadır. Bu gibi endüstrilerde kullanılan kuvars kumunu, talep edilen tane boyutuna optimum sürede getirebilmek için doğru bilya boyutunun seçilmesi oldukça önemlidir. Bu çalışmada kuvars kumu örneğinin kırılma hızı değerlerinin değişimi, iki farklı boyuttaki alümina bilya kullanılarak incelenmiştir. Bu amaçla, 0.090-0.053 mm aralığında $\sqrt[4]{2}$ elek serisine göre üç dar tane boyut fraksiyonu hazırlanmıştır. Hazırlanan bu üç fraksiyondaki kuvars kumu, 10 ve 30 $\mathrm{mm}$ boyutlarındaki alümina bilyalar ile farklı sürelerde öğ̈̈ülmüştür. Öğütme periyotları sonunda elde edilen tane boyut dağılımlarından özgül kırılma hızı değerleri elde edilmiştir. Öğ̈̈tme testleri sonucunda, bilya boyutunun artmasına bağlı olarak kırılma hızında azalma gözlenmiştir.

Anahtar Kelimeler: Kuvars kumu, Ufalama, Kırılma hızı, İnce öğütme.

\section{The Research about the Effects of Grinding Media Size on the Determination of Breakage Rate of Quartz Sand}

\begin{abstract}
In the ceramic industry, the grinding units make up the first stage of raw material preparation process. It takes a long time to reduce the raw materials with no essence to a certain grain size such as feldspar and quartz sand that make up the mill phase. This situation causes negativity in terms of time and energy consumption. In this respect, it is very important to select the correct ball size in order to bring the quartz sand to the desired particle size in optimum time. In this study, the changes in the specific rate of breakage of the quartz sand sample was investigated by using alumina ball in two different sizes. For this purpose, three different mono-size intervals between the range of $0.090-0.053 \mathrm{~mm}$ were prepared according to the $\sqrt[4]{2}$ sieve series. The quartz sand prepared in these three intervals were grounded with 10 and $30 \mathrm{~mm}$ alumina balls for different durations. Specific rate of breakage values were obtained from the particle size distributions acquired after the grinding periods. As a result of grinding tests, an decrease in rate of breakage is observed due to the increase in ball diameter.
\end{abstract}

Keywords: Quartz sand, Comminution, Breakage rate, Fine grinding.

\footnotetext{
*Sorumlu Yazar: serhan.haner@gmail.com
} 


\section{Giriş}

Kuvars kumu, magmatik metamorfik kayaçların ayrışması sonucu oluşmaktadır. Tane boyutu 2 mm'den küçük olan kuvars içeriğine sahiptir. Beyaz renklidir. Ancak içerisindeki demir oksit miktarına bağlı olarak pembe, kahverengi veya kızıl renklerde olabilir. Yüksek oranda silis içermektedir. Doğada saf olarak bulunabilmesine karşın az miktarlarda feldispat, kil, karbonatlar veya demir oksitler içerebilmektedir. Kullanım amaçlarına bağlı olarak talep edilen fiziksel, kimyasal veya 1sıl özelliklerin kazandırılabilmesi amacıyla birtakım cevher hazırlama işlemleri uygulanmaktadır. Kuvars kumu genel olarak cam ve döküm sanayisinde tüketilmektedir. $\mathrm{Bu}$ kullanım alanlarının dışında seramik, inşaat, plastik, boya, aşındırıcı gibi sanayilerde de kullanılmaktadır. Ocaktan üretim yöntemi olarak açık işletme metodu uygulanmaktadır. Kuvars kumu üretiminin ekonomik olabilmesi için örtü tabakasının kalınlığının kuvars kumu tabakasının kalınlığına oranı $4 \mathrm{~m}^{3} /$ ton seviyesini aşmamalıdır (DPT, 2001).

Seramik sağlık gereçleri fabrikaları tarafından temin edilen kuvars kumlarının yaklaşık \%90'1 (-2+0.075) mm boyutundaki tanelerden oluşmaktadır. Seramik sağlık gereçleri üretiminde feldispat ve kuvars kumu gibi özsüz hammaddelere ögütme işlemi uygulanmakta ve öğütme süresi sonunda özsüz bileşimin $0.060 \mathrm{~mm}$ tane boyutunun altında olması istenmektedir. Seramik tesisleri tarafindan genellikle bilyalı değirmenler tercih edilmektedir ve ögütücü malzeme cinsi olarak ise alümina bilya kullanılmaktadır. Öğütme işlemi $0.1 \mathrm{~mm}$ tane boyutunun altında olduğundan dolayı kullanılan enerjinin büyük bir kısmı 1s1 enerjisine dönüşmektedir. Ekonomik açıdan öğütme verimliliğinin azaldığı bu ince tane boyutlarında bilyalı değirmenlerin özgül enerjileri üstel olarak artış göstermektedir (Liddell, 1986; Haner, 2020).

Kuvars kumunun tek başına ince tane boyutlarına ögütülmesi, hem zaman hem de enerji açısından yüksek tüketimlere sebep olmaktadır. Kuvars kumu, seramik üretiminde bilyalı değirmen fazını oluşturan diğer özsüz hammaddeler üzerinde ögütücü ortam gibi davranmaktadır. Ayrıca öğütücü ortamı oluşturan alümina bilya yüzeyinin de aşınmasına sebep olmaktadır. Bu nedenle değirmendeki diğer hammaddelere göre kuvars kumunun ögütülmesi düşük seviyelerde olmaktadır. Genellikle kuvars kumu tanelerinin kırılması, çatlak yüzeylerinden konkoidal parça kopması şeklinde gerçekleşmektedir. Çünkü kuvarsın dilinimi yoktur (Vardar ve Bozkurtoğlu, 2009). Bu nedenle kırma ve ögütme işlemleri esnasında kuvars kumu örnekleri düzgün kırılma göstermemektedir. Kırılma konkoidal (midye kabuğu) şekilde ve düzensiz olmaktadır. Düzensiz gelişmiş çatlakların kırılmaya etken olduğu söylenebilir (Haner, 2016).

Değirmenlerde kapasite ve verimliliği etkileyen önemli bir değişken öğütücü ortam boyutudur. Bilyalı değirmen ile yapılan orta dereceli öğütme $(0.040-0.40 \mathrm{~mm})$ işleminde optimum öğütücü ortam boyutu seçimi ile ilgili literatürde bazı çalışmalar mevcuttur (Bond, 1958; Austin ve ark., 1976; Yusupov ve ark., 2003; Coghill ve Devaney, 2019; Haner, 2020).

$\mathrm{Bu}$ çalışmada, farklı boyutlardaki alümina bilyanın kuvars kumunun kırılma hızına $\left(S_{i}\right)$ etkisi araştırılmıştır. Öğütme çalışmalarında kullanılan kuvars kumu, özel bir seramik şirketi tarafından temin edilmiştir. Kuvars kumunun özgül kırılma hızının değişimi 10 ve $30 \mathrm{~mm}$ boyutlarındaki alümina bilya kullanılarak incelenmiştir. Kuru ortamda gerçekleştirilen öğütme deneyleri için değirmendeki malzeme doluluk oranı $\left(f_{c}\right) 0.096$ ve bilya doluluk oranı $(J) 0.30$ olarak alınmıştır. Bu amaçla, Lynch tarafından temeli oluşturulan ve Austin tarafından geliştirilen kinetik model uygulanmıştır. $\mathrm{Bu}$ modelde bir hammaddenin kırılma dağılımını ve kırılma hızını tanımlayan matematiksel ifadeler bulunmaktadır (Austin ve ark., 1984). Kinetik model tabanlı ögütme çalışmaları ile laboratuvar çapında elde edilen değerler, endüstriyel ortamda simülasyona uygundur (Austin ve ark., 1981).

\section{Materyal ve Metot}

Öğ̈̈tme çalışmalarında kullanılan kuvars kumu, Zonguldak ili Gökçebey ilçesinde bulunan özel bir seramik şirketinden temin edilmiştir. Kuvars kumuna ait kimyasal analiz değerleri Tablo 1'de verilmiştir.

$\mathrm{Bu}$ çalışmada, kuvars kumunun üç tane boyut fraksiyonundaki özgül kırılma hızı değerleri (Si) belirlenmiştir. Bunun için kuvars kumunun $4 \sqrt{ } 2$ elek serisine göre üç dar tane boyut aralığ1 $(-0.090+0.075,-0.075+0.063,-0.063+0.053 \mathrm{~mm})$ hazırlanmıştır. Kuvars kumunun özgül kırılma hızı değerlerinin tespiti için, $15 \times 15 \mathrm{~cm}$ (çapxuzunluk) ölçüsüne sahip ve çelik malzemeden üretilmiş laboratuvar boyutlu bir bilyalı değirmen kullanılmıştır. Bilyalı değirmen içerisinde tercih edilen öğütücü ortam ise 10 ve $30 \mathrm{~mm}$ çapındaki alümina bilyalar olmuştur. $4 \sqrt{2}$ elek serisine göre hazırlanmış olan her bir dar tane boyut aralığı, kırılma fonksiyonlarının belirlenmesi için kesikli olarak öğütülmüştür. Her bir öğütme periyodu (1, 2, 4, 8, 16, 32, 64 ve 128 dakika) sonrası değirmen içerisindeki kuvars kumunun tamamı boşaltılmış ve tane boyutu ölçümü için örnek alınmıştır. Öğütme periyotlarına ait numunelerin tane boyut dağılımlarının tespiti amaciyla Malvern Hydro 2000G marka ve model cihaz kullanılmıştır. Zamana karşılık her bir öğütme periyodu sonucu en üst tane boyutu aralığında kalan malzeme fraksiyonlarının öğütme sürelerine karşı yarı logaritmik grafikleri çizilmiştir. Birinci derece kırılma bölgesi, bu grafiğin doğrusal bir şekilde azaldığı bölge ile temsil edilmektedir. Birinci derece kırılma bölgesindeki doğrunun eğimi bize malzemenin o tane boyut aralığındaki özgül kırılma hızını vermektedir. Özgül kırılma hızına ait formül Eşitlik 1'de görülmektedir.

$$
S_{i}=a\left(\mathrm{x}_{\mathrm{i}} / 1 \mathrm{~mm}\right)^{\alpha} Q_{i}
$$

Eşitlik 1 'de verilen " $a$ " sembolü, model parametresidir. $\mathrm{Bu}$ parametre, hammadde ve ögütme şartlarına bağlıdır. " $x_{i}$ ", i fraksiyonundaki üst boyutu $(\mathrm{mm})$ sembolize etmektedir. $Q$ düzeltme faktörüdür ve küçük boyutlu taneler için 1 olarak alınır. $\alpha$ değeri pozitif bir sayıdır ve malzeme özelliklerine bağlı olarak 0.5 ile 1.5 arasında değişir (Austin ve ark., 1984).

Deneysel çalışmalarda bilyalı değirmenin dönüş hızı olarak, değirmenin kritik hı değerinin \%75'i tercih edilmiştir. Değirmen dönüş hızı Eşitlik 2 kullanılarak hesaplanmıştır. Eşitlik 3 ve 4 ile sırasıyla değirmene beslenecek malzeme miktarları $\left(f_{c}\right)$ ve değirmenin boşluk doldurma oranları $(U)$ bulunmuştur.

$$
\operatorname{Kritik} \operatorname{hız}\left(N_{k}\right)=\frac{42.3}{\sqrt{(\mathrm{D}-\mathrm{d})}}
$$

Eşitlik 2'de, D değirmen çapını (m), d ise bilya çapını (m) temsil etmektedir.

$$
f_{c}=\frac{\text { Malzeme Miktarı/Malzeme Yoğunluğu }}{\text { Değirmen Hacmi }} *\left(\frac{1}{0.6}\right)
$$


$U=\frac{f_{C}}{0.4 * J}$

Öğütme deneylerinde kullanılan bilyalı değirmene ait özellikler ve deneysel koşullar Tablo 2'de verilmiştir.

Tablo 1. Kuvars Kumunun \% Oksit Değerleri

\begin{tabular}{l|c}
\hline $\mathrm{SiO}_{2}$ & 91.16 \\
\hline $\mathrm{Al}_{2} \mathrm{O}_{3}$ & 5.18 \\
\hline
\end{tabular}

Tablo 2. Bilyalı Değirmenin Özellikleri ve Deneysel Koşulları

\begin{tabular}{l|l|c}
\hline \multirow{4}{*}{ Değirmen } & İç çap, $\mathrm{mm}$ & 150 \\
\cline { 2 - 3 } & İç uzunluk, mm & 150 \\
\cline { 2 - 3 } & Hacim, $\mathrm{cm}^{3}$ & $\sim 2650$ \\
\cline { 2 - 3 } & Çalışma hızı, dev/dak & $\sim 91-84.5$ \\
\hline \multirow{4}{*}{ Bilya } & Malzeme & Alümina \\
\cline { 2 - 3 } & Boyut, $\mathrm{mm}$ & $10-30$ \\
\cline { 2 - 3 } & Ortalama bilya ağılılıları, $\mathrm{g}$ & $\sim 3.5-72$ \\
\cline { 2 - 3 } & Özgül ağırlık, $\mathrm{g} / \mathrm{cm}^{3}$ & 3.70 \\
\cline { 2 - 3 } & Doluluk oranı $(J)$ & 30 \\
\hline \multirow{4}{*}{ Malzeme } & Gerçek yoğunluk, $\mathrm{g} / \mathrm{cm}^{3}$ & 2.65 \\
\cline { 2 - 3 } & Malzeme yükü $\left(f_{c}\right)\left(J=0.30, N_{c}=0.75\right)$ & 0.096 \\
\cline { 2 - 3 } & $f_{c}$ 'ye göre boşluk doldurma oranı $(\% U)$ & 0.80 \\
\hline
\end{tabular}

\section{Araştırma Sonuçları ve Tartışma}

İki ayrı tane boyut fraksiyonundaki kuvars kumu, iki farklı boyuttaki bilya kullanılarak, lineer olarak artan öğütme sürelerinde öğütülmüştür. Her bir öğütme periyodu sonunda, en üst tane boyutu aralığında kalan malzeme fraksiyonlarının, ögütme sürelerine karşı grafikleri çizilmiştir. Birinci derece

\begin{tabular}{l|l}
\hline $\mathrm{Na}_{2} \mathrm{O}$ & 0.62 \\
\hline $\mathrm{K}_{2} \mathrm{O}$ & 0.37 \\
\hline $\mathrm{CaO}$ & 0.05 \\
\hline $\mathrm{Fe}_{2} \mathrm{O}_{3}$ & 0.34 \\
\hline $\mathrm{TiO}_{2}$ & 0.43 \\
\hline $\mathrm{SO}_{3}$ & 0.03 \\
\hline K1zdirma Kayb1 & 1.82 \\
\hline
\end{tabular}

kırılma doğrularının grafikleri Şekil 1, 2 ve 3'de ve sonuçları Tablo 3'de verilmiştir. Birinci derece kırılma bölgesi, bu grafiğin doğrusal bir şekilde azaldığı bölge ile temsil edilmektedir. Birinci derece kırılma bölgesindeki doğrunun eğimi, malzemenin tane boyut aralığına bağlı özgül kırılma hızını vermektedir.

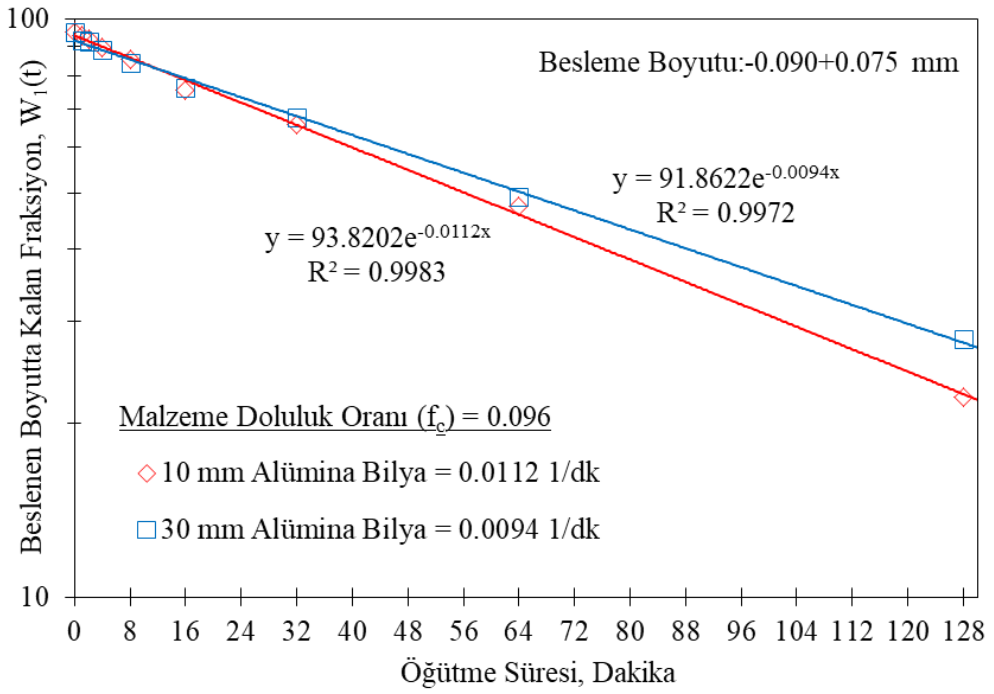

Şekil 1. Kuvars Kumunun -0.090+0.075 mm Tane Boyut Aralı̆̆ için Birinci Derece Kırılma Doğruları 
Avrupa Bilim ve Teknoloji Dergisi

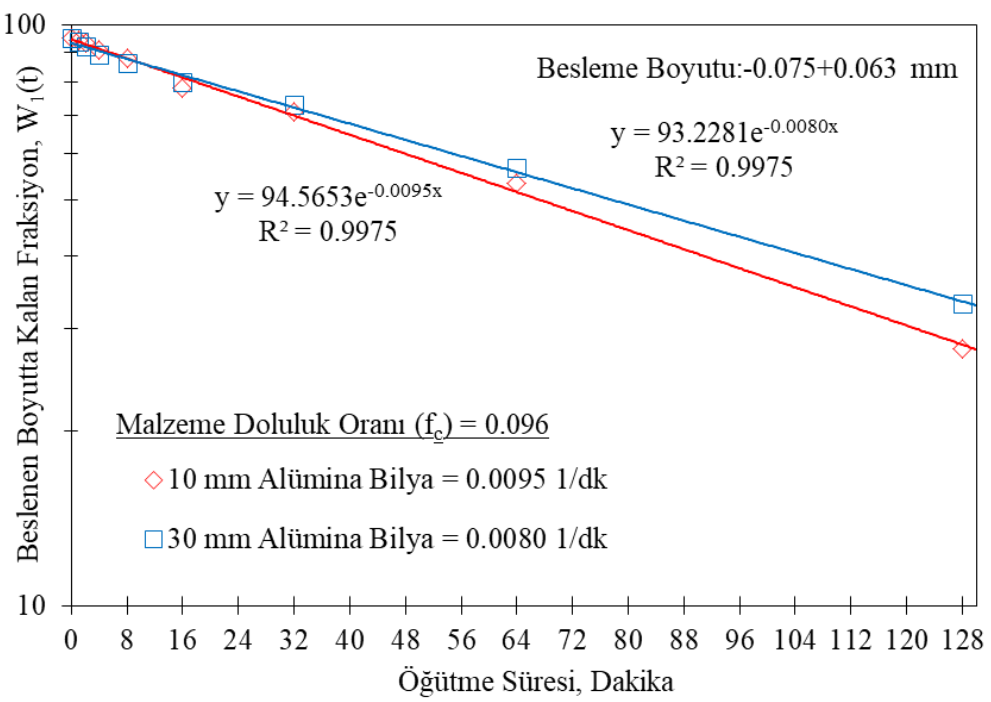

Şekil 2. Kuvars Kumunun -0.075+0.063 mm Tane Boyut Aralığı için Birinci Derece Kırılma Doğruları

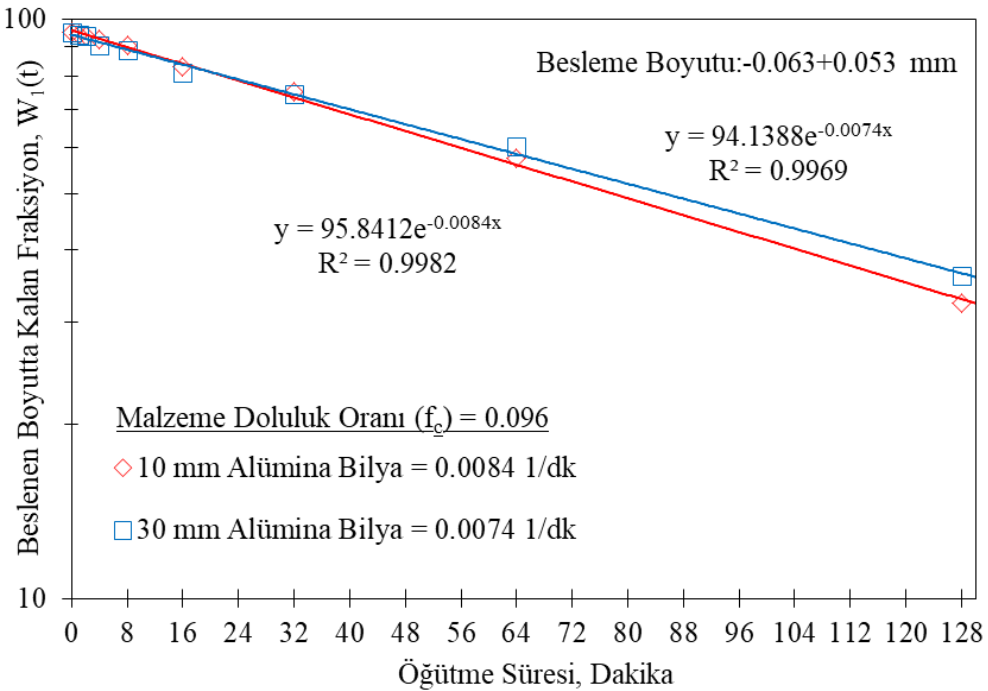

Şekil 3. Kuvars Kumunun -0.063+0.053 mm Tane Boyut Aralı̆̆ iç̧in Birinci Derece Kırılma Doğruları

Geleneksel bilyalı değirmenlerde büyük boyutlu bilyaların kaba tanelerin öğütülmesinde ve küçük boyutlu bilyaların ise ince tanelerin öğ̈̈tülmesinde daha etkin olduğu kabul edilmektedir. Austin ve ark. (1984)'e göre, bilya çapının kırılma hızına olan etkisini, değirmenin birim hacmindeki bilya çapının azalmasına bağlı olarak bilya çarpışma hızının artması olarak açıklamaktadır. Yani ince tanelerin kırılma hızları bilya çapı küçüldükçe artmaktadır. $\mathrm{Bu}$ çalışmada da, $10 \mathrm{~mm}$ alümina bilyanın malzemenin kırılmasında daha etkin olduğu sonucuna varılmıştır.

Tablo 3. Kuvars Kumunun Farklı Boyutlardaki Bilyalar için Özgül Kırılma Hızları

\begin{tabular}{l|c|c}
\hline \multirow{2}{*}{ Besleme Boyutu, mm } & \multicolumn{2}{|c}{$S_{i}, \mathrm{dk}^{-1}$} \\
\cline { 2 - 3 } & $10 \mathrm{~mm}$ & $30 \mathrm{~mm}$ \\
\hline$-0.090+0.075$ & 0.0112 & 0.0094 \\
\hline$-0.075+0.063$ & 0.0095 & 0.0080 \\
\hline$-0.063+0.053$ & 0.0084 & 0.0074 \\
\hline
\end{tabular}

Şekil 4'de büyük boyutlu bilyaların tanelerin üzerine aktarmış olduğu ögütme enerjisi yetersiz kaldığından özgül kırılma hızı da düşmeye başlamıştır. Küçük bilyalar ile daha etkin bir kırılmanın gerçekleştiği görülmektedir.

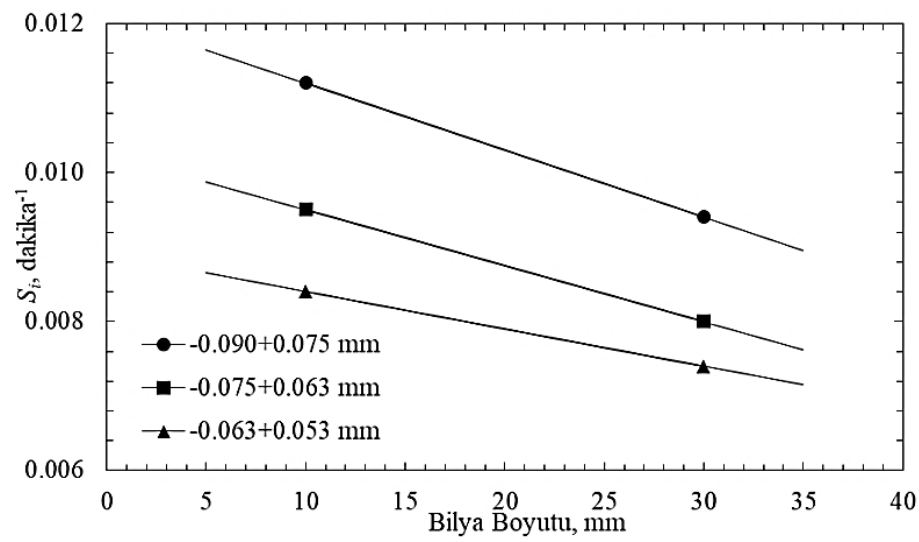

Şekil 4. Birinci Derece Kırılma Hızı ile Bilya Çapının Değişıimi 


\section{Sonuç}

Kuvars kumu örneğinin 10 ve $30 \mathrm{~mm}$ boyutlu alümina bilya için kuru ortamda yapılan deneylerde hazırlanan tek tane boyut fraksiyonundaki malzemeler lineer olarak artan öğütme sürelerinde öğütülmüşlerdir. Zamana karşllık her bir ögütme sonucu en üst tane boyutu aralığında kalan malzeme fraksiyonlarının öğütme sürelerine karşı yarı logaritmik grafikleri çizilmiştir. Birinci derece kırılma bölgesi, bu grafiğin doğrusal bir şekilde azaldığı bölge ile temsil edilmektedir. Üç dar besleme tane boyut fraksiyonundaki kuvars kumunun, 10 ve $30 \mathrm{~mm}$ alümina bilya ile yapılan öğütme işlemi sonucunda, gerçekleşen kırılmanın, birinci derece kırılma kinetiğine uygun olduğu görülmüştür.

$S_{i}$ değeri büyüdükçe, hammaddenin kırılma mekanizmasının etkinleştiği anlaşılır. Ayrıca bu durum, orijinal parçanın alt tane boyut aralıklarına hızlı bir şekilde ineceğini de göstermektedir. Şekil 1, 2 ve 3 ile Tablo 3, her bilya boyutu kendi içerisinde besleme boyutuna göre değerlendirildiğinde, küçük tane boyutlarında düşük kırılma hız değerlerinin elde edildiği görülmektedir. Tane boyutunun küçülmesi ile görülen kırılma hızındaki azalma, öğütücü ortam olarak kullanılan bilyalar tarafından tanelerin yakalanıp kırılmasının zorlaşması nedeniyledir (Austin ve ark., 1984; Klimpel, 1997). Diğer taraftan kuvars kumunun tane boyutu küçüldükçe, kırılmaya etken olan düzensiz gelişmiş çatlakların azalması nedeniyle kırılma hızı azalmıştır. Çatlak teorisi, büyük tane boyutundaki hammaddelerin tane boyutları küçüldükçe daha az çatlak içereceğini belirtmektedir. Ayrıca, geometrik etki göz önünde bulundurulduğunda, iri taneler bilyalar tarafindan kolaylıkla kavranabilmekte ancak küçük tanelerin kavranması daha zor olmaktadır. Böylece tane boyutu küçüldükçe hammaddenin kırılması zorlaşmaktadır.

Kuvars kumu örneğinin, 10 ve $30 \mathrm{~mm}$ boyutundaki alümina bilyalarla yapılan öğütme çalışmaları kıyaslandığında; $10 \mathrm{~mm}$ alümina bilyanın malzemenin kırılmasında daha etkin olduğu sonucu çıkarılmıştır.

$\mathrm{Bu}$ çalışmada tek bir malzeme ve bilya doluluk oranı araştırılmıştır. Farklı malzeme ve bilya doluluk oranlarında farklı sonuçlar elde edilebilir. Çünkü ögüttme esnasında bilyalar arasında kalan bölgenin malzeme ile doldurulma miktarı, öğütme verimini belirleyici etkenlerden birisidir. Öğütme verimliliği bilya-bilya, bilya-malzeme, malzeme-malzeme, malzeme-değirmen, bilya-değirmen temasındaki değişim oranları ile değişmektedir.

Sonuç olarak, literatür incelendiğinde, endüstrinin çeşitli kollarında kullanılan bazı hammaddelere ait kırılma verileri bulunamamaktadır. Zaten herhangi bir bölgeye ait hammaddenin kırılma parametreleri, içeriğindeki mineral oranına göre de değişmektedir. Bu nedenle cevher hazırlama tesislerinde, ögütme için harcanan enerji miktarını azaltmak için hammaddelerin öğütme kinetiklerinin ölçülmesinde fayda vardır.

\section{Kaynakça}

Austin, L.G., Shoji, K. and Luckie, P.T., 1976. The effect of ball size on mill performance, Powder Technology, 4, 71-79.

Austin, L.G., Bagga, R. and Çelik, M., 1981. Breakage properties of some materials in a laboratory ball mill, Powder Technology, 28, 235-241.
Austin, L.G., Klimpel, R.R. and Luckie, P.T., 1984. Process Engineering of Size Reduction: Ball Milling, New Jersey: American Institute of Mining Metallurgical and Petroleum Engineers Inc.

Bond, F.C., 1958. Grinding ball size selection, Mining Engineering, 592-595.

Coghill W.H. and Devaney, F.D., 1937. Ball Mill Grinding.

https://play.google.com/books/reader?id=k4MbYBy8674C\&hl=t $\mathrm{r} \& \mathrm{pg}=$ GBS.PP1. (15.12.2019)

DPT, 2001. Devlet Planlama Teşkilatı, Madencilik Özel İhtisas Komisyonu Raporu, Endüstriyel Hammaddeler Alt Komisyonu Toprak Sanayii Hammaddeleri III, 2613-624, Ankara.

Haner, S., 2016. Seramik sağlık gereçleri hammaddelerinin öğütme ve pişirim şartlarının ürünlerin kalitesi üzerine etkileri. Doktora tezi, Süleyman Demirel Üniversitesi Fen Bilimleri Enstitüsü, Isparta, 293.

Haner, S., 2020. The effects of ball size on the determination of breakage parameters of nepheline syenite, Journal of Mining Science, 56, 5, 2020.

Klimpel, R.R., 1997. Introduction to the Principles of Size Reduction of Particles by Mechanical Means, Instructional Module Series, NSF Engineering Research Center for Particle Science \& Technology, Florida.

Liddell, K.S., 1986. Machines for fine milling to improve the recovery of gold from calcines and pyrite, Proceeding of the International Conference on Gold, Johannesburg, 405-417.

Vardar, M. ve Bozkurtoğlu, E., 2009. Yerkabuğunu Oluşturan Maddeler Mineraller ve Kayaçlar, İnşaat Jeolojisi, 20 s., 2009-2010 Ders Yılı Notları.

Yusupov, T.S. Kirillova, E.A. and Denisov, G.A., 2003. Dressing of quartz-feldspar ores on the basis of selective grinding and mechanical activation, Journal of Mining Science, 39, 2, 174-177. 